\title{
Spatial genetic heterogeneity in a population of the montane perennial plant Delphinium nelsonii
}

\author{
Nickolas M. Waser
}

\author{
Department of Biology, University of California, \\ Riverside CA 92521 U.S.A. and Rocky Mountain \\ Biological Laboratory, Crested Butte, CO 81224 \\ U.S.A.
}

The montane perennial herb Delphinium nelsonii experiences restricted pollen and seed movement and spatial environmental heterogeneity, features likely to promote genetic differentiation within populations. To explore this possibility, allele frequencies at 5 polymorphic loci were characterised along transects through a meadow. F-statistics indicated substantial heterozygote excess within transect samples (overall $F_{I S}=-0 \cdot 096$ ). Possible contributors are sex-biased gene flow, and events occurring between pollination and ovule fertilisation that favor pollen from an "optimal outcrossing distance" of 3-10 m. Higher mating success over this optimal distance should cause longer realised gene dispersal than expected from pollen and seed movement, which are $<1 \mathrm{~m}$ on average. It also may bring about a "leapfrog" dispersal pattern instead of a monotonic decline with distance from a source plant. F-statistics also indicated moderate genetic differentiation among samples (overall $F_{S T}=0.069$ ). However, this did not correspond to organised spatial pattern. Spatial autocorrelations showed that alleles were randomly distributed along transects. Although mean genetic distance increased with physical distance, the pattern was not statistically significant. Apparent random spatial heterogeneity is expected if gene flow is extensive enough to prevent a rapid decline in genetic correlation with distance; it also might be promoted by a leapfrog pattern of gene flow.

\section{INTRODUCTION}

A prevailing view of plant populations is that they are genetically heterogeneous in space (Allard, 1975; Levin, 1977). This view arose from the realisation that gene flow and selection regimes are often localised (Levin and Kerster, 1974; Endler, 1977; Turkington and Harper, 1979). Restricted gene flow may permit local adaptation (Jain and Bradshaw, 1966; Dickinson and Antonovics, 1973; Slatkin, 1985), and can foster genetic isolation-bydistance even when selection does not change spatially (Wright, 1951; Kimura and Weiss, 1964; Malécot, 1969; Rohlf and Schnell, 1971; Endler, 1977; Sokal and Wartenberg, 1983).

This paper describes a study of spatial genetic variation in the montane wildflower Delphinium nelsonii. Genotypes sampled from a single meadow were characterised using electrophoresis, and variation was analysed by F-statistics and spatial autocorrelation. In addition, Nei's (1972, 1978) genetic distance was calculated between plant samples separated by various physical distances.

Based on earlier estimates of gene flow (Price and Waser, 1979; Waser and Price, 1983) and extant models of populations structure (Wright, 1951; Kimura and Weiss, 1964; Malécot, 1969; $\mathrm{Nei}, 1972$ ), my initial expectation was that genetic variation would exhibit clear spatial pattern. The actual results were more intriguing. Although spatial heterogeneity in allele frequencies occurred, it could not be shown tō deviate from random expectation (sensu Sokal and Oden, $1978 b$; Endler, 1977, p. 30ff). In addition, there was consistent local heterozygote excess. Both results may be caused by the mating system of $D$. nelsonii.

\section{METHODS}

The study system

Delphinium nelsonii Greene (Ranunculaceae) is a small (15-30 cm tall), slow-growing herbaceous perennial. At the Rocky Mountain Biological Laboratory (RMBL, $2900 \mathrm{~m}$ elevation) in Colorado, pollinators are bumblebees (Bombus appositus and B. flavifrons) and hummingbirds (Selasphorus platycercus) (Waser, 1982), and there 
is no vegetative reproduction or prolonged seed dormancy. Bees and birds have similar visitation behaviours, including distances flown between plants (Waser, 1982). These are predominantly short, leading to localised pollen movement. Mean and median pollen dispersal distances are $<1 \mathrm{~m}$, and axial variance of pollen dispersal is $0.9 \mathrm{~m}^{2}$ (Price and Waser, 1979; Waser and Price, 1983, 1985; previous estimates corrected after Crawford, $1984 a$ ). The relatively heavy seeds (about $1 \mathrm{mg}$ ) fall on average $11 \mathrm{~cm}$ from the maternal parent; axial variance in seed dispersal is $0.01 \mathrm{~m}^{2}$ (Waser and Price, 1983).

Based on these values, inbreeding-effective genetic neighbourhoods (Wright, 1969) were originally calculated to cover $5.5 \mathrm{~m}^{2}$ and contain 28 plants (Waser and Price, 1983). This picture is not changed appreciably by correcting for kurtosis of pollen and seed dispersal (Crawford 1984b; estimated $g_{2}=8.7$ for pollen and 0.1 for seeds). However, recent evidence suggests that neighbourhood size may substantially exceed the original estimate, because dispersal distance influences the chances that a pollen grain fertilises an ovule and that the resulting seedling survives. Specifically, an "optimal outcrossing distance" of 3-10 m appears to maximise pollen fertilisation success and offspring survival (Price and Waser, 1979; Waser and Price, 1983; Waser et al., 1987). Thus pollen from this distance, which exceeds the mean dispersal distance, may gain disproportionate representation among adults. This aspect of the mating system should elevate realised gene flow and neighbourhood size (Crawford, 1984b).

There also is evidence that selection regimes are localised in meadows where $D$. nelsonii grows. The array of herbaceous species changes over short distances, indicating changes in biotic and/or edaphic conditions, and reciprocal seed transplants over $50 \mathrm{~m}$ show that there is adaptation to conditions near the maternal parent (Waser and Price, 1985).

\section{Sampling within a single meadow}

In June 1981 a representative meadow was located at $3000 \mathrm{~m}$ elevation, two $160 \mathrm{~m}$ transects were laid out at right angles (fig. 1), and sampling points were established every $5 \mathrm{~m}$; the longest intersample distance was $213 \mathrm{~m}$. Mature seeds were harvested from plants growing within $1 \mathrm{~m}$ of each point. Thus the area sampled was about $3 \mathrm{~m}^{2}$, which approximates the original neighbourhood area estimate given above. Seeds from different fruits on a plant were pooled. Because of herbivory and fruit abortion only 3-6 plants could be sampled per transect point; all 26 samples involved seeds from $>2$ plants and half involved seeds from $>4$.

\section{Electrophoresis}

Seeds were stored without refrigeration and transported to California in September 1981. Untreated seeds were crushed in a drop of $0.1 \mathrm{M}$ Tris- $\mathrm{HCl}$

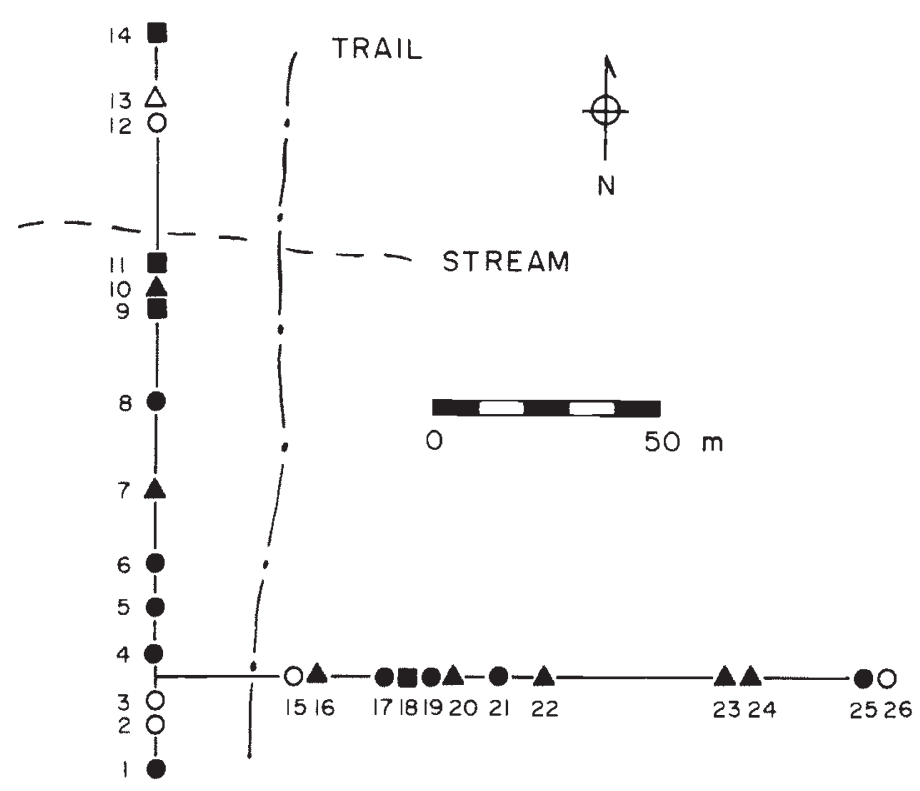

Figure 1 Map of transects. Sampling points are numbered symbols. Those of like kind (open circles, filled circles, filled squares, etc.) clustered at a genetic distance $<0 \cdot 005$. 
$p \mathrm{H} 7 \cdot 0$ with $0.01 M$ dithiothreitol, crude extract absorbed in wicks of Whatman \#3 filter paper, and electrophoresis performed horizontally on 11.7 per cent electrostarch gels cooled with ice.

Of 25 enzyme systems screened, only 5 produced banding patterns that were straightforward to interpret. Staining for these systems revealed 2 monomorphic and 5 polymorphic loci (table 1).

Table 1 Overall allele frequencies at 5 polymorphic PGM (phosphoglucomutase), MDH (malate dehydrogenase), and M6PI (mannose-6-phosphate isomerase) loci. One additional PGM locus and one additional MDH locus were monomorphic

\begin{tabular}{lllll}
\hline Locus & \multicolumn{5}{c}{ Allele } \\
\hline & 1 & 2 & 3 & 4 \\
PGM & 0.49 & 0.38 & 0.13 & - \\
MDH-1 & 0.13 & 0.87 & - & - \\
MDH-2 & 0.97 & 0.03 & - & - \\
M6PI-1 & 0.08 & 0.87 & 0.05 & - \\
M6PI-2 & 0.06 & 0.26 & 0.65 & 0.03 \\
\hline
\end{tabular}

The final gel systems used were a Triscitrate/lithium-borate system for PGM (Scandalios, 1969), a histidine-citrate system for $\mathrm{MDH}$ (Jeffries and Gottlieb, 1982), and a 0.065M Tris-

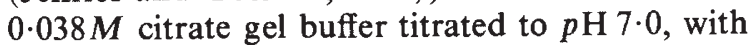
an electrode buffer of $0.2 M \mathrm{NaOH}-0.6 \mathrm{M}$ borate

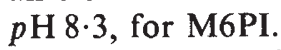

At least 6 seeds were analysed per plant, and allozyme patterns were used to determine maternal genotypes by half-sib progeny analysis. This analysis, along with comparative information from other species, also yielded a consistent interpretation of the allelic nature of electromorphs ( $c f$. Gottlieb, 1981).

\section{Analyses}

Variation in maternal gene and genotype frequencies was characterised using hierarchical fixation indices (Wright, 1951). These are $F_{I S}$, the correlation between alleles in an individual relative to its subpopulation; $F_{S T}$, the correlation between random alleles in a subpopulation relative to the overall population; and $F_{I T}$, the correlation between alleles in an individual relative to the population. $F_{I S}$ indicates local deviation from heterozygosity expected under random mating, while $F_{S T}$ indicates spatial genetic heterogeneity (sensu Sokal and Oden, 1978b). I used methods of Weir and Cockerham (1984) to calculate sample estimates of $F$-statistics and their variances, and to combine values across alleles.
I also ran spatial autocorrelations (Sokal and Oden, $1978 a, b)$ on allele frequencies. Moran's $I$, a correlation coefficient for all samples separated by a given range of distances, was calculated with the Fortran program SAAP written by D. Wartenberg. Distance intervals of $20 \mathrm{~m}$ were used; class boundaries were $0-20 \mathrm{~m}, 21-40 \mathrm{~m}, \ldots, 141-160 \mathrm{~m}$. Using smaller distance intervals does not alter conclusions. A separate analysis was run for the most common allele at each locus, and a mean $I$ value across loci was calculated for each distance interval. Means could be compared to null expectation by a t-test since $I$ values for a given interval were distributed without significant skew or kurtosis.

Finally, Nei's (1978) unbiased standard genetic distance, $D$, was calculated between each of 325 possible pairs of transect sampling points, incorporating all 7 loci assayed. $D$ ranges from zero when samples have identical allele frequencies to infinity when they are fixed for different alleles. Regression and unweighted pairwise cluster analyses were used to compare $D$ with the physical separation of samples. Successive pairwise comparisons of sampling points are not independent, so in lieu of standard parametric tests computer simulation was used to place sample allele frequencies at transect locations by a pseudo-random process. Genetic distance values were calculated for this "null" arrangement and regressed on physical distance; this was iterated 2000 times.

\section{RESULTS}

$F_{I S}$ was negative at 4 of 5 loci, indicating heterozygote excess within individual samples, and the overall value of -0.096 was significantly less than zero (table 2). $F_{S T}$ was positive at 3 loci, and the overall value of 0.069 was significantly greater than zero. The total fixation index, $F_{I T}$, was slightly negative at 4 loci, but the overall value of -0.020 did not differ from zero. M6PI-1 deviated from other loci in its large positive fixation indices while the MDH loci deviated in their negative $F_{S T}$ values. Omitting sample 13, a genetic "outlier" (see below), did not change qualitative results (table 2) or statistical conclusions.

Weir and Cockerham (1984) stress that commonly-used methods for calculating F-statistics assume knowledge of actual populational allele frequencies. Errors may occur when sample estimates are used instead. For example, Wright's (1951) formula for $F_{S T}$ gives a mean of 0.187 across loci, about three times the estimate obtained here. 
Table 2 F-statistics. Values in parentheses exclude sample 13. The estimator for $F_{S T}$ (Weir and Cockerham, 1984) can give negative values

\begin{tabular}{llll}
\hline Locus & $F_{I S}$ & $F_{S T}$ & $F_{I T}$ \\
\hline PGM & $-0.129(-0.103)$ & $0.035(0.044)$ & $-0.088(-0.049)$ \\
MDH-1 & $-0.130(-0.103)$ & $-0.010(-0.001)$ & $-0.137(-0.157)$ \\
MDH-2 & $-0.013(-0.054)$ & $-0.031(-0.024)$ & $-0.044(-0.079)$ \\
M6PI-1 & $0.117(0.115)$ & $0.253(0.040)$ & $0.341(0.151)$ \\
M6PI-2 & $-0.135(-0.129)$ & $0.068(0.065)$ & $-0.058(-0.055)$ \\
Overall & $-0.096^{*}(-0.089)$ & $0.069 \dagger(0.041)$ & $-0.020 \ddagger(-0.044)$ \\
\hline
\end{tabular}

$* t=-5 \cdot 5, \mathrm{df}=4, P<0.02$ 2-tailed; jackknife method.

$\dagger t=3.9, \mathrm{df}=4, P<0.02$ 2-tailed.

$\ddagger t=-0 \cdot 6, \mathrm{df}=4, P>0 \cdot 52$-tailed.

Spatial autocorrelation analysis yielded 40 separate $I$ values ( 8 distance intervals $\times 5$ loci); only one differed from null expectation at $P<0.05$. The only apparent pattern was that values for all 5 loci were negative in the intervals $0-20 \mathrm{~m}$ and 100 $120 \mathrm{~m}$. This is illustrated by a summary correlogram using mean $I$ values (fig. 2) Of 8 mean values, those for the intervals $0-20 \mathrm{~m}$ and 100 $120 \mathrm{~m}$ deviated most strongly (2-tailed $P=0 \cdot 10$ and $P<0.05$, respectively) from null expectation $(E(I)$ in Fig. 2). Negative autocorrelation at 0-20 m suggests extremely local heterogeneity. Omitting sample 13 (see below) did not appreciably change $I$ values or qualitative conclusions.

Genetic distances between samples were highly variable. The mean was $0.024(s=0.044$, range $0-0 \cdot 224)$. Genetic distance seemed to increase slowly with separation in the meadow; the leastsquares linear fit was $y=0.015+0.0001 x(y=$ genetic distance, $x=$ physical distance in $\mathrm{m}$ ). However, this explained only a tiny fraction of variance in $y\left(r^{2}=0.014\right)$, and exponential and logarithmic models explained even less. From computer simulation the exact probability by chance alone of obtaining a regression slope greater than the actual slope (Type I error) was $0 \cdot 17$.

Cluster analysis (fig. 3 ) showed that 3 pairs or triplets of adjacent samples clustered at genetic distances $<0.005$, suggesting patches of like genotype on a scale of 5-20 m (samples 2 and 3; 4,5 , and 6; 23 and 24; fig. 1). All 18 samples not found in such patches differed from immediate neighbors at genetic distances $>0.01$. Sample 13

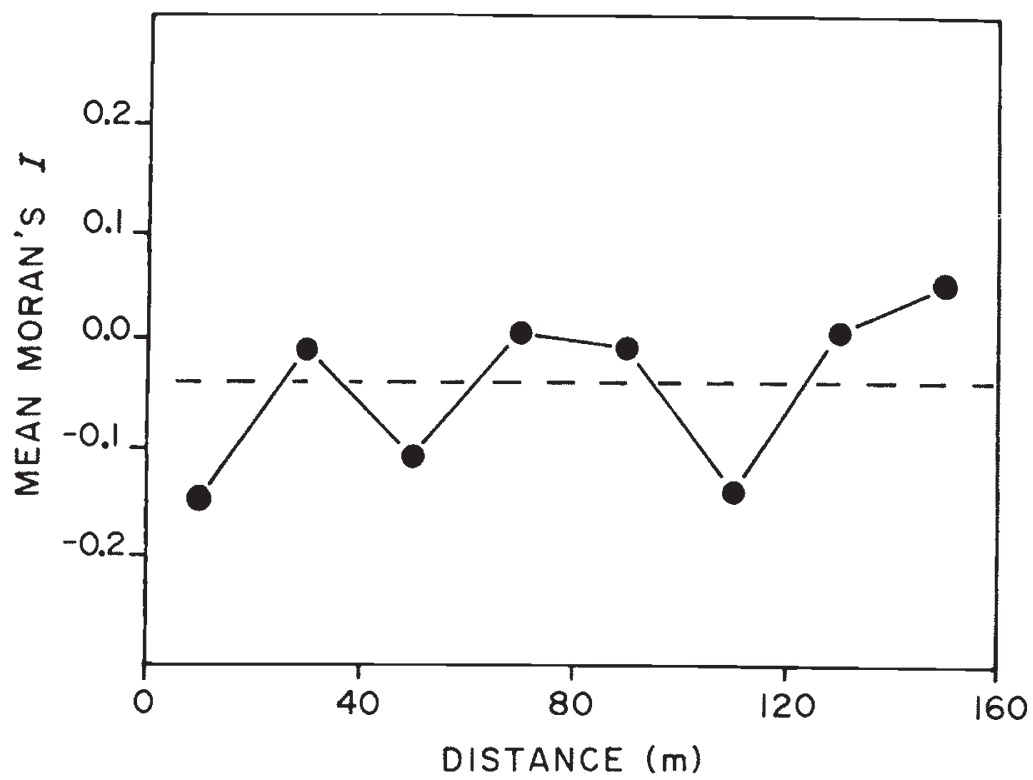

Figure 2 Correlogram using mean values of Moran's $I$ and 8 distance intervals of $20 \mathrm{~m}$. The horizontal dashed line at $-0 \cdot 04$ indicates $E(I)$, the expected value of $I$. 


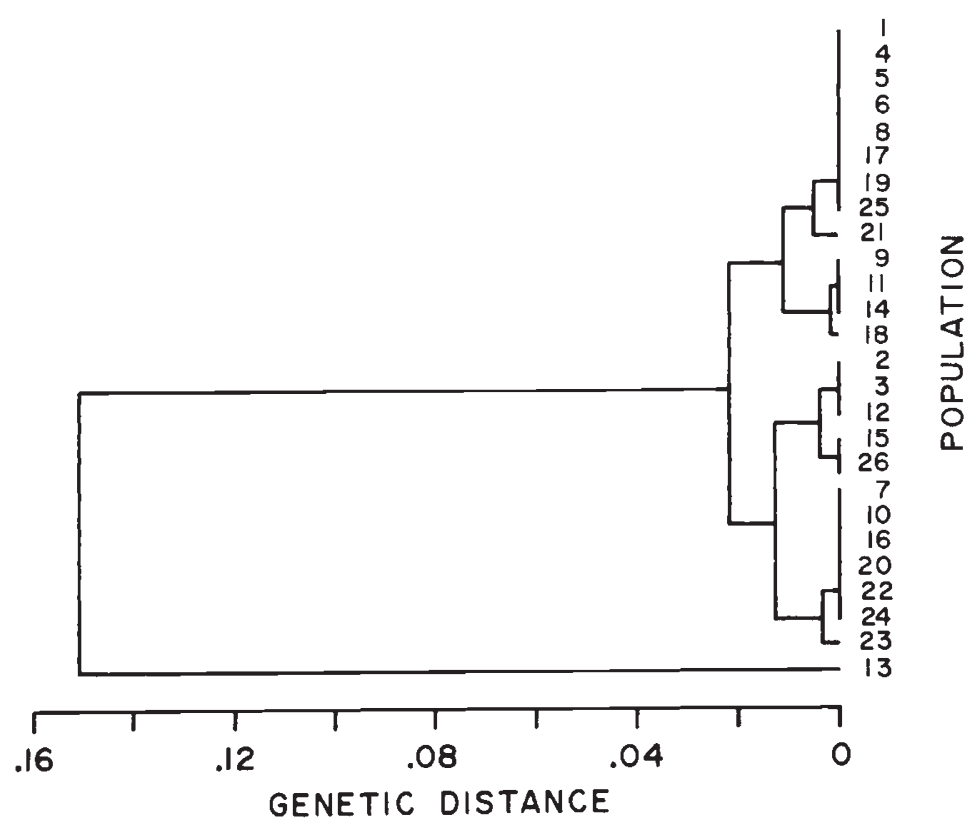

Figure 3 Cluster analysis based on Nei's $D$. Numbering of samples corresponds to fig. 1 .

differed from others at a level of $0 \cdot 152$. This was due mostly to the M6PI-1 locus, where sample 13 was monomorphic for the otherwise rare allele 1 (table 1). Omitting sample 13 eliminates the large $F_{S T}$ value for M6PI-1, and changes the relationship of genetic and physical distance to $y=$ $0 \cdot 015-0.0001 x\left(r^{2}=0 \cdot 002\right)$.

\section{DISCUSSION}

The negative $F_{I S}$ values indicate substantial local heterozygote excess relative to random mating expectation. This does not necessarily indicate heterozygote advantage, however. Prout (1981) showed, for an island population model, that sexbiased gene flow promotes heterozygote excess because allele frequencies differ between subpopulations and thus between mated individuals (see also Dickinson and Antonovics, 1973). Gene flow in outcrossing plants is automatically male-biased (Crawford, 1984a); the bias is especially large if pollen dispersal exceeds seed dispersal, as in $D$. nelsonii. Given the possibility of very local allele frequency variation, suggested by negative autocorrelation in the shortest distance class (fig. 2 ), pollen often may contribute an allele that is rare among recipient females. In addition, pollen from donor plants at the optimal outcrossing distance of 3-10 $\mathrm{m}$ appears more likely to fertilise ovules than pollen from shorter or longer distances
(Waser et al., 1987). This may represent greater success of outbred, more heterozygous, crosses (Price and Waser, 1979; Waser and Price, 1983; Campbell and Waser, 1987).

Differential success of pollen from 3-10 m and survival of seedlings from the resulting crosses (Waser et al., 1987) should inflate realised gene dispersal. Thus genetic neighbourhoods probably ccntain more than the 28 plants estimated from pollen and seed movement. Two lines of evidence support this assertion. First, assuming that the meadow traversed by transects contains $10^{3}$ neighbourhoods, Wright's (1951, fig. 7; compare Rohlf and Schnell, 1971, figs. 3 and 14) continuous population model requires a neighbourhood size $>50$ to produce the observed $F_{S T}$ of $0 \cdot 069$. Second, the "conditional average frequency" of alleles (fig. 4) exhibits a pattern characteristic of substantial gene flow with a stepping-stone population model (see Slatkin, 1981).

Differential mating success over the optimal outcrossing distance also may be large enough to cause a "leapfrog" pattern in which effective gene dispersal at some distance from a source plant exceeds that adjacent to the plant. This contrasts with a more familiar monotonic decline away from the source.

The significant positive mean $F_{S T}$ indicates moderate spatial genetic variation in the study meadow. The value of 0.069 is similar to those taken to indicate local differentiation in the plants 


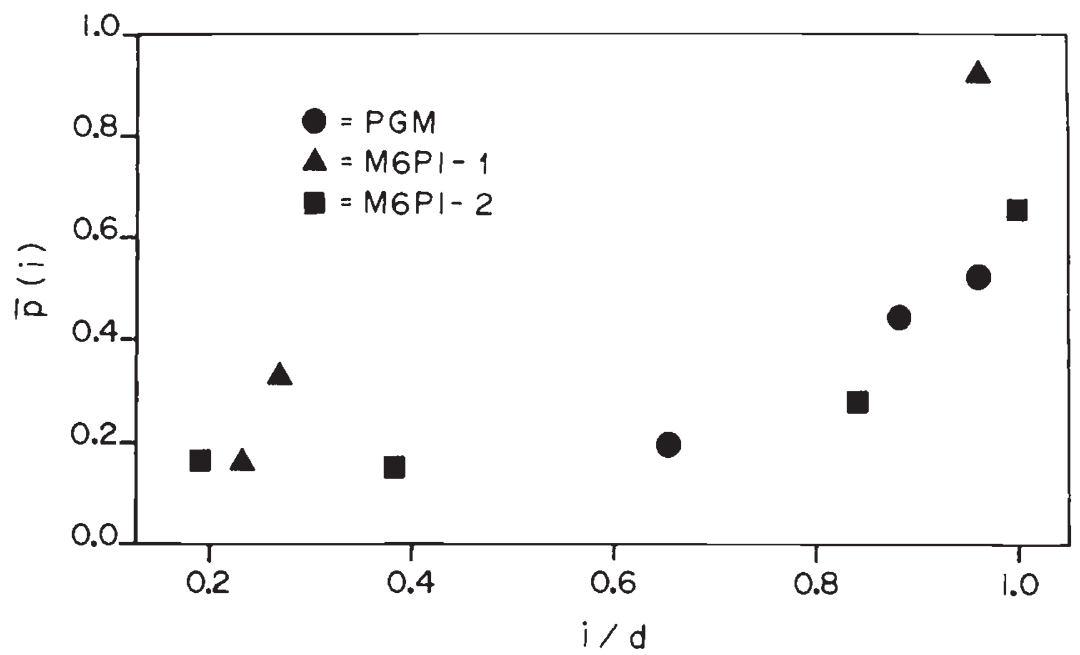

Figure 4 Conditional average frequencies of alleles $(p(i))$ as function of proportion of samples containing each allele $(i / d)$, for loci with $>2$ alleles. The pattern resembles those produced by moderate to extensive gene flow $(m=0.05$ and $m=0.1)$ with a two-dimensional stepping-stone population structure (Slatkin 1981, fig. $2 b$ ).

Liatris cylindraceae (Schaal, 1975) and Plantago lanceolata (Bos et al., 1986), and in the snail Helix aspersa (Selander and Kaufman, 1975). Spatial heterogeneity also is suggested by patches of similar genotype (fig. 3) and by some relatively large $D$ values. On the other hand, genetic variation did not exhibit any dramatic spatial pattern, either when loci were considered separately (autocorrelation) or jointly (autocorrelation, genetic distance). Although mean genetic distance increased with physical distance, the pattern was not distinguishable from random expectation (see Slatkin, 1985). Bos et al. (1986) discussed a similar situation with $P$. lanceolata.

The D. nelsonii results, and those of Bos et al. (1986), seem at odds with reports of extremely local isolation by distance by Schaal (1974) and Selander and Kaufman (1975). However, these authors presented mean rather than raw $D$ values, which strengthens the apparent relationship between genetic and physical distance. In the case of $D$. nelsonii, using mean values from successive $10 \mathrm{~m}$ distance intervals in the regression of genetic on physical distance does not alter the equation based on raw values, but elevates $r^{2}$ from 0.01 to $0 \cdot 26$. Furthermore, neither Schaal (1974) nor Selander and Kaufman (1975) performed a statistical analysis. Sokal and Oden (1978b, table 2, fig. 4) ran spatial autocorrelations on Schaal's (1975) data, and found little evidence of significant pattern.

Random genetic heterogeneity certainly is not a standard expectation from deterministic models of population structure. Rather, gene frequency clines are anticipated with selection and limited gene flow (Jain and Bradshaw, 1966, Endler, 1977; Slatkin 1985). They also are expected with genetic drift. For example, Wright (1951) predicted decreasing genetic correlation over distance with isotropic gene flow in a continuous population, and Malécot (1969) arrived at a similar conclusion that incorporated mutation (without which the absorbing state is global fixation, although this may take so long as to be uninteresting). Kimura and Weiss (1964) and Nei (1972) discussed how genetic distance increases with physical distance given a stepping-stone population structure and infinite alleles mutation.

Random heterogeneity should occur under some conditions, however. First, selection regimes themselves might be distributed without spatial pattern. Second, many loci, probably including those assayed here, are not subject to strong spatially-varying selection. Such effectivelyneutral loci may exhibit random heterogeneity if connectedness among subpopulations via gene flow is unrelated to physical distance, (an island population structure; Bos et al., 1986), or if there is little connectedness at all among subpopulations (Sokal and Oden, 1978a).

A final possibility involves extensive rather than restricted gene flow. This will prevent a rapid decline in genetic correlation with distance, so that local spatial pattern will be subtle and difficult to detect. In Wright's (1951, p. 351, fig. 7) continuous population model, for example, the genetic corre- 
lation declines to about 0.7 at 30 neighbourhood radii, given a neighbourhood size of $20-50$. The maximum distance of about $200 \mathrm{~m}$ surveyed here corresponds to $>30$ radii using my initial neighbourhood estimate. But if neighbourhoods are twice this large or larger, as suggested above, the maximum distance is close to 30 radii, and all correlations of allele frequencies among samples should equal or exceed $0 \cdot 7$. A spatial pattern this weak, in terms of absolute allele frequency change might be obscured easily by stochastic temporal and spatial variation in gene flow (Slatkin, 1985; Slatkin and Maruyama, 1975).

Although I have followed well-established practice in attempting to match an observed population pattern with theoretical predictions, this approach is of questionable power. Different evolutionary forces may well foster indistinguishable patterns, and available theory is not sufficiently well-developed to handle many biologically realistic conditions. In the case of $D$. nelsonii, for example, I have invoked the genetic neighbourhood concept, a simplification that suffers from theoretical and empirical difficulties (e.g., Crawford, 1984a,b). The scenario given above also ignores the possible leapfrog nature of gene flow, which might contribute to spatial heterogeneity. At present it seems impossible to analyse the situation further, in the absence of theoretical treatments of population structure, or of summary statistics such as Nei's $D$ or Moran's $I$, that consider complex patterns of gene flow (Slatkin, 1985). Such treatments would be very useful.

Finally, it should be stressed that lack of detectable spatial structure at the loci assayed does not preclude structure at other loci. In $D$. nelsonii there is evidence for adaptation to local conditions (as noted above; Waser and Price, 1985), and the loci involved may exhibit clinal variation. Unless electrophoretic loci happen to be involved in local adaptation or closely physically linked to selected loci, they will not exhibit clines (Clegg, 1984). Thus electrophoretic "markers" cannot be assumed to mark events, occurring at selected loci, that may be of particular interest in a given study.

Acknowledgements Electrophoresis was done in the laboratory of N. Ellstrand by J. Lee, with assistance from C. Mount and S. Wood. I an indebted to them all. For discussions, comments on the manuscript, or field assistance I thank J. Antonovics, H. Burla, D. Campbell, N. Ellstrand, J. Felsenstein, C. Galen, L. Raczek, D. Samson, M. Uyenoyama, C. Wolin, and M. Price. Support was provided by US National Science Foundation Grants DEB 81-02774 and BSR 83-13522.

\section{REFERENCES}

ALLARD, R. W. 1975. The mating system and microevolution. Genetics, 79, 115-126.

BOS, M., HARMENS, H. AND VRIELING, K. 1986. Gene flow in Plantago I. Gene flow and neighbourhood size in P. lanceolata. Heredity, 56, 43-54.

CAMPBELL, D. R. AND WASER, N. M. 1987. The evolution of plant mating systems: Multilocus simulations of pollen dispersal. Amer. Natur., in press.

CLEGG, M. T. 1984. Dynamics of multilocus genetic systems. Oxford Surv. Evol. Biol., 1, 160-183.

CRAWFORD, T. J. 1984a. The estimation of neighbourhood parameters for plant populations. Heredity, 52, 273-283.

CRAWFORD, T. J. 1984b. What is a population? In Shorrocks, B., (ed.) Evolutionary Ecology, Blackwell, Oxford, U.K., pp. 135-173.

DICKINSON, H. AND ANTONOVICS, J. 1973. Theoretical considerations of sympatric divergence. Amer. Natur., 107, 256-274.

ENDLER, J. A. 1977. Geographic Variation, Speciation, and Clines, Princeton Univ. Press, Princeton, New Jersey, U.S.A.

GOTTLiEB, L. D. 1981. Electrophoretic evidence and plant populations. In Reinhold, L., Harborne, J. B. and Swain, T. (eds.) Progress in Phytochemistry, Volume 7, Pergamon, Oxford, U.K., pp. 1-46.

JAIN, S. K. AND BRADSHAW, A. D. 1966. Evolutionary divergence among adjacent plant populations. I. The evidence and its theoretical analysis. Heredity, 20, 407-441.

JEFFRIES R. L. AND GOTTLIEB, L. D. 1982. Genetic differentiation of the microspecies Salicornia europea L. (sensu stricto) and S. ramosissima J. Woods, New Phytol., 92, 123-129.

KIMURA, M. AND WEISS, G. H. 1964. The stepping-stone model of population structure and the decrease of genetic correlation with distance. Genetics, 49, 561-576.

LEVIN, D. A. 1977. The organization of genetic variability in Phlox drummondii. Evolution, 31, 477-494.

LEVIN, D. A. AND KERSER H. W. 1974. Gene flow in seed plants. Evol. Biol., 7, 139-220.

MALÉCOT, G. 1969. The Mathematics of Heredity, Freeman, San Francisco, California, U.S.A.

NEI, M. 1972. Genetic distance between populations. Amer. Natur., 106, 283-292.

NEI, M. 1978. Estimation of average heterozygosity and genetic distance from a small number of individuals. Genetics, 89 , 583-590.

PRICE, M. V. AND WASER, N. M. 1979. Pollen dispersal and optimal outcrossing in Delphinium nelsoni. Nature, 277, 294-297.

PROUT, T. 1981. A note on the island model with sex dependent migration. Theor. Appl. Genet., 59, 327-332.

ROHLF, F. J. AND SCHNELL, G. D. 1971. An investigation of the isolation-by-distance model. Amer. Natur., 105, $295-$ 324.

SCANDALIOS, J. C. 1969. Genetic control of multiple molecular forms of enzymes in plants: A review. Biochem. Genet., 3 , 37-79.

SCHAAL, B. A. 1974. Isolation by distance in Liatris cylindraceae. Nature, 252, 703.

SCHAAL, B. A. 1975. Population structure and local differentiation in Liatris cylindraceae. Amer. Natur, 109, 511-528.

SELANDER R. K. AND KAUFMAN, D. W. 1975. Genetic population structure and breeding systems. In Markert, C. L. (ed.) Isozymes, Volume 4, Academic Press, New York, U.S.A., pp. $27-48$. 
SLATKIN, M. 1981. Estimating levels of gene flow in natural populations. Genetics, 99, 323-335.

Slatkin, M. 1985. Gene flow in natural populations. Ann. Rev. Ecol. System., 16, 393-430.

SLATKIN, M. AND MARUYAMA, T. 1975. The influence of gene flow on genetic distance. Amer. Natur., 109, 597-601.

SOKAL, R. R. AND ODEN, N. L. 1978a. Spatial autocorrelation in biology. 1. Methodology. Biol. J. Linn. Soc., 10, 199-228.

SOKAL, R. R. AND ODEN, N. L. 1987b. Spatial autocorrelation in biology. 2. Some biological implications and four applications of evolutionary and ecological interest. Biol. J. Linn. Soc. 10, 229-249.

SOKAL, R. R. AND WARTENBERG, D. E. 1983. A test of spatial autocorrelation analysis using an isolation-by-distance model. Genetics, 105, 219-237.

TURKINGTON, R. AND HARPER, J. L. 1979. The growth, distribution, and neighbor relationships of Trifolium repens in a permanent pasture. J. Ecol., 67, 245-254.

WASER, N. M. 1982. A comparison of distances flown by different visitors to flowers of the same species. Oecologia, $55,251-257$.
WASER, N. M. AND PRICE, M. V. 1983. Optimal and actual outcrossing in plants, and the nature of plant-pollinator interaction. In Jones, C. E. and Little, R. J. (eds.) Handbook of Experimental Pollination Biology, Van Nostrand Reinhold, New York, U.S.A., pp. 341-359.

WASER, N. M. AND PRICE, M. V. 1985. Reciprocal transplant experiments with Delphinium nelsonii (Ranunculaceae): Evidence for local adapation. Amer. J. Bot., 72, 1726-1732.

WASER, N. M., PRICE, M. V., MONTALVO, A. M. AND GRAY, R. N. 1987. Female mate choice in a perennial herbaceous wildflower, Delphinium nelsonii. Evolutionary Trends in Plants, in press.

WEIR, B. S. AND COCKERHAM, C. C. 1984. Estimating F-statistics for the analysis of population structure. Evolution, 38 , 1358-1370.

WRIGHT, S. 1951. The genetical structure of populations. Ann. Eugen., 15, 323-354.

WRIGHT, S. 1969. Evolution and the Genetics of Populations, Volume 2. The Theory of Gene Frequencies, Univ. Chicago Press, Chicago, Illinois, U.S.A. 